\title{
PROTECTIVE EFFECT OF GREEN TEA ON DENTIN EROSION AND ABRASION
}

\author{
Melissa Thiemi KATO ${ }^{1}$, Ana Carolina MAGALHÃES², Daniela RIOS ${ }^{3}$, Angélica Reis HANNAS 4 , \\ Thomas ATTIN ${ }^{5}$, Marília Afonso Rabelo BUZALAF ${ }^{6}$
}

\begin{abstract}
1- DDS, MSc, Master's degree in Public Health, Bauru School of Dentistry, University of São Paulo, Bauru, SP, Brazil.
2- DDS, MSc, PhD, Professor, Discipline of Biochemistry, Department of Biological Sciences, Bauru School of Dentistry, University of São Paulo, Bauru, SP, Brazil.

3- DDS, MSc, PhD, Professor, Department of Pediatric Dentistry, Orthodontics and Community Health, Bauru School of Dentistry, University of São Paulo, Bauru, SP, Brazil.

4- DDS, MSc, PhD, Post-doctoral fellow, Department of Biological Sciences, Bauru School of Dentistry, University of São Paulo, Bauru, SP, Brazil. 5- DDS, MSc, PhD, Professor of Clinic for Preventive Dentistry, Periodontology and Cariology, University of Zürich, Switzerland.

6- DDS, MSc, PhD, Full Professor, Discipline of Biochemistry, Department of Biological Sciences, Bauru School of Dentistry, University of São Paulo, Bauru, SP, Brazil.
\end{abstract}

Corresponding address: Profa. Dra. Marília Afonso Rabelo Buzalaf - Departmento de Ciências Biológicas - Faculdade de Odontologia de Bauru Universidade de São Paulo - Al. Octávio Pinheiro Brisolla, 9-75 - Bauru, SP - 17012-901 - Brasil - Phone: + 55 14-3235-8346 - Fax +55-14-3226-2076 - e-mail: mbuzalaf@fob.usp.br

Received: December 12, 2008 - Modification: February 17, 2009 - Accepted: February 27, 2009

\begin{abstract}
$O$

bjective: This in situ study evaluated the protective effect of green tea on dentin erosion (ERO) and erosion-abrasion (ABR). Material and methods: Ten volunteers wore intraoral palatal appliances with bovine dentin specimens subjected to ERO or ERO + toothbrushing abrasion performed immediately (ERO+I-ABR) or $30 \mathrm{~min}$ after erosion (ERO+30-min-ABR). During 2 experimental 5 -day crossover phases, the volunteers rinsed with green tea or water (control, $1 \mathrm{~min}$ ) between each erosive (5 min, cola drink) and abrasive challenge ( $30 \mathrm{~s}$, toothbrushing), $4 \mathrm{x} /$ day. Dentin wear was measured by profilometry. Results: The green tea reduced the dentin wear significantly for all conditions compared to control. ERO+I-ABR led to significantly higher wear than ERO, but it was not significantly different from ERO+30-min-ABR. ERO+30-min-ABR provoked significant higher wear than ERO, only for the placebo treatment. Conclusions: From the results of the present study, it may be concluded that green tea reduces the dentin wear under erosive/abrasive conditions.
\end{abstract}

Key words: Dentin. Green tea. Tooth erosion. Tooth abrasion.

\section{INTRODUCTION}

Severe dental erosion is accompanied by dentin exposure, which might be associated with painful hypersensitivity and is accompanied by an increased risk for further dentin wear by different chemical and physical processes, such as erosion and abrasion ${ }^{32}$.

In dentin, the erosive demineralization results in the exposure of an outer layer of fully demineralized organic matrix followed by a partly demineralized zone until the sound inner dentin is reached ${ }^{16}$. The degradation of the dentin matrix occurs after it has become accessible by the removal of mineral, i.e., the dentin matrix cannot be degraded unless it is demineralized ${ }^{18}$. The dentin demineralization rate decreases when the amount of degradable collagen increases, whereby the demineralized matrix is attributed to hamper ionic diffusion into and out of the demineralizing area ${ }^{17,18}$.
However, the organic matrix can be degraded mechanically and chemically, which can contribute to an enhanced progression of dentin wear ${ }^{8,9,12}$.

Among the proteases that can chemically degrade the organic matrix of dentin are matrix metalloproteinases (MMPs) present in dentin and saliva ${ }^{31}$. MMPs are responsible for hydrolyzing the components of the extracellular matrix $(E C M)$ during remodeling and degradation processes in the oral environment. MMPs related to the degradation of the collagen matrix of dentin are especially MMPs 2, 8, and 9 $9^{21,30,31}$. MMPs get activated when the $\mathrm{pH}$ drops in the presence of acids from cariogenic challenges. The subsequent neutralization by salivary buffer systems enhances the degrading activity of the organic matrix $^{31}$. In addition, phosphorylated proteins released during the demineralization of the organic matrix can interact with inhibited host MMPs within the lesion and reactivate 
them, thus enhancing the degrading activity. The activation of MMPs seems to be important for the progression of dentin caries, since they have a crucial role in the collagen breakdown in caries lesions. Individuals with a high concentration of MMPs in saliva present an increased susceptibility to dental caries ${ }^{5}$. Despite the lack of studies investigating the role of MMPs in dental erosion, processes similar to those occurring for caries could be speculated to occur for erosive lesions. In this sense, the maintenance of the organic matrix on eroded dentin would be likely to postpone further erosion progression, which could be achieved by the use of MMP inhibitors. This strategy has been successfully employed, by using chlorhexidine as an MMP inhibitor, for reduction of the degradation of the dentin hybrid layer both in vivo ${ }^{15}$ and in vitro ${ }^{4}$.

Due to the above-mentioned considerations, it might be interesting to find MMP inhibitors ${ }^{3}$ that could play a role on the reduction of dental erosion. Green tea polyphenols, especially epigallocatechin-3-gallate (EGCG), were found to have distinct inhibitory activity against MMPs ${ }^{5,7,10,28}$. Thus, the aim of this in situ study was to test the protective effect of green tea on dentin erosion (ERO). Considering that the softened zone by erosive challenge seems to be more susceptible to mechanical forces, such as abrasion ${ }^{1,20}$, the protective effect of green tea on erosion associated to immediate abrasion (ERO+I-ABR) or abrasion 30 min after the erosive challenge $(\mathrm{ERO}+30-\mathrm{mim}-\mathrm{ABR})$ was investigated as well.

\section{MATERIAL AND METHODS}

\section{Specimen preparation}

One hundred and twelve crown dentin specimens ( 4 x 4 x $3 \mathrm{~mm}$ ) were prepared from extracted bovine incisors, which had been stored in $0.1 \%$ thymol solution $\left(\mathrm{pH} \mathrm{7.0)}\right.$ at $4^{\circ} \mathrm{C}$ for 30 days. One specimen was obtained from the labial surface of each crown. For preparation of dentin specimens, enamel was completely removed until dentin was just exposed. The exposed dentin was ground flat with water-cooled carborundum discs and polished with felt paper wet with 1 $\mu \mathrm{m}$ diamond spray (Buehler, Lake Bluff, IL, USA), resulting in a removal of about $100 \mu \mathrm{m}$ of the outermost layer. For allocation of the specimens to the groups, the surface microhardness was determined by performing five indentations in different regions of the specimens (Knoop diamond, 10 g, 5 s, HMV-2000; Shimadzu Corporation, Tokyo, Japan). The overall range of microhardness was 55$75 \mathrm{KHN}$. Specimens were allocated to groups by stratified randomization according to the mean surface microhardness. All groups presented similar mean microhardness (around $65 \mathrm{KHN})$.

In order to maintain reference surfaces for lesion depth determination by profilometry, two layers of nail varnish were applied on half of the surface of each specimen. Individual acrylic palatal appliances with 6 palatal cavities were used for intraoral exposure of the specimens. In three rows, each two specimens were arranged on the left and right sides of the appliance.

\section{Ethical aspects}

This study was approved by the Institutional Review Board of Bauru Dental School, University of São Paulo, Brazil (Process 021/2007) and volunteers participated after signing an informed consent form. Ten healthy adult volunteers (aged 20-30 years) residing in a fluoridated area (0.6-0.8 $\mathrm{mg} \mathrm{F} / \mathrm{L})^{24}$, who fulfilled the inclusion criteria described below, took part in this study. They presented normal salivary parameters, such as adequate stimulated and non-stimulated salivary flows $(>1.0$ and $0.5 \mathrm{~mL} / \mathrm{min}$, respectively) and salivary $\mathrm{pH}(=6.8)$. The subjects were free from erosive lesions, untreated carious cavities or periodontitis. The number of volunteers in the present study was defined according to previous studies ${ }^{19,25,35}$.

\section{Intraoral phase}

This in situ study involved 10 volunteers and was performed in two crossover 5-day phases, with a washout period of 7 days. In the first $12 \mathrm{~h}$ of each intraoral phase, specimens were not subjected to erosive and abrasive treatments to allow the formation of a salivary pellicle ${ }^{13}$. On the following 5 days, erosive and abrasive challenges were made extraorally 4 times a day at predetermined times $(8,12,16$ and $20 \mathrm{~h})$ after the principal meals.

For erosion of the dentin specimens, the volunteers were instructed to remove the appliance and immerse it in a cup containing $150 \mathrm{~mL}$ of regular Coke ( $\mathrm{pH}$ 2.6; Coca-cola Company Spal, Porto Real, RJ, Brazil) for 5 min at room temperature. During this period, the volunteers were instructed to prepare the green tea, according to manufacturers' instructions (Yamamotoyama; Midori Indústria de Chá Ltda, São Miguel Arcanjo, SP, Brazil): infusion of $2 \mathrm{~g}$ of the herb (Cammelia sinensis leaves exposed to steam and presented as a sachet) into $180 \mathrm{~mL}$ of boiled water $\left(100^{\circ} \mathrm{C}\right)$ for $1 \mathrm{~min}$. The tea was cooled off for $4 \mathrm{~min}$ at room temperature. The fluoride content of the tea was $0.87 \mathrm{mg}$ fluoride/ $\mathrm{L}$ and its $\mathrm{pH}, 7.0$. The concentration of EGCG in the green tea was $0.185 \mathrm{mg} / \mathrm{mL}(400 \mu \mathrm{M})$, as measured by high-performance liquid chromatography, according to Saito, et al. ${ }^{26}$ The same procedure (including previous heating and cooling off) was performed with water from the public supply (0.6-0.8 mg fluoride/L), which was used as control. The temperature of the green tea and water immediately before the rinse was around $50^{\circ} \mathrm{C}$.

After the $5 \mathrm{~min}$ of erosive challenge, the volunteers took one sip of the beverage. Thus, the appliances were re-inserted into the mouth and the volunteers rinsed with $10 \mathrm{~mL}$ of green tea or water for $1 \mathrm{~min}$. Subsequently, the appliance was removed for abrasion treatment. While one row remained unbrushed (ERO), the other row was brushed ex vivo using a soft end-rounded electric toothbrush (Colgate Montions Multi-action; Colgate-Palmolive Ind. and Com. Ltda., SP, Brazil) with $\sim 0.3 \mathrm{~g}$ of non-fluoridated dentifrice (Procter and Glamble Co, Cincinnati, USA) for $30 \mathrm{~s}$ (166 oscillations/ s) each specimen (ERO+I-ABR). The appliances were replaced into the mouth and the volunteers rinsed with water 
TABLE 1- Wear $(\mu \mathrm{m})$ of dentin specimens subjected to erosion or erosion + abrasion (immediate or after 30 min) treated with green tea or water. Mean \pm SD $(95 \% \mathrm{Cl})$

\section{Conditions}

Treatment

Erosion

Erosion + immediate abrasion

Erosion + 30-min-abrasion

\begin{tabular}{llll}
\hline Water $^{\mathrm{A}}$ & $0.98 \pm 0.13^{\mathrm{a}}$ & $1.23 \pm 0.35^{\mathrm{b}}$ & $1.22 \pm 0.23^{\mathrm{b}}$ \\
Control $)^{\mathrm{b}}$ & $(0.89-1.07)$ & $(0.98-1.48)$ & $(1.05-1.38)$ \\
Green tea $^{\mathrm{B}}$ & $0.59 \pm 0.18^{\mathrm{a}}$ & $0.90 \pm 0.32^{\mathrm{b}}$ & $0.74 \pm 0.23^{\mathrm{ab}}$ \\
& $(0.46-0.72)$ & $(0.67-1.13)$ & $(0.57-0.91)$ \\
\hline
\end{tabular}

Different uppercase letters in the columns indicate statistically significant differences between the treatments. Different lowercase letters in the rows indicate statistically significant differences among the conditions (2-way repeated-measures ANOVA, $p<0.05$ ).

$(10 \mathrm{~mL}, 5 \mathrm{~s})$. After $30 \mathrm{~min}$ of erosion, the abrasive treatment was repeated for the $3^{\text {rd }}$ row $(\mathrm{ERO}+30$-min-ABR). The rows for the 3 experimental conditions were randomly allocated for each volunteer.

The volunteers received instructions to wear the appliances continuously for $24 \mathrm{~h}$ but to remove them during meals (4 times/day), when the appliance was stored in wet gauze. Seven days prior to the beginning and throughout the experimental phase, the volunteers brushed their teeth with a non-fluoridated dentifrice (Procter and Gamble Co, Cincinnati, OH, USA). They were also instructed to avoid licking of the specimens with the tongue to avoid abrasion ${ }^{11}$. The volunteers received oral and written information to refrain from using any fluoridated or antibacterial product.

\section{Wear analysis}

After the in situ phase, the specimens were removed from the appliances and kept moistened (gauze soaked in water) up to the wear analysis in order to avoid shrinkage of the dentin organic material. The nail varnish over the reference surfaces was carefully removed ${ }^{20}$. The dentin wear was determined in relation to the reference surfaces by contact profilometry (Hommel Tester T 1000, Hommelwerke, VS, Schwenningen, Germany). Five readings were performed on each specimen by scanning from the reference to the exposed surface. The mean values of five readings for each group were averaged.

\section{Statistical Analysis}

The assumptions of equality of variances and normal distribution of errors were checked for all the variables tested, using the Bartlett and Kolmogorov-Smirnov tests, respectively. Since the assumption was satisfied, two-way repeated measures ANOVA and Bonferroni post hoc test were used. The factors evaluated were treatment (green tea or water) as the dependent variable and condition (ERO, ERO+I-ABR and ERO+30-min-ABR) as the independent variable. The significance level was set at $5 \%$. The software GraphPad Prism 4 version 4.0 for Windows (Graph Pad Software Inc., San Diego, CA, USA) was used.

\section{RESULTS}

There was statistically significant difference among the conditions $(\mathrm{F}=4.50, \mathrm{p}=0.021)$ and between the treatments $(F=65.45, p<0.0001)$. Table 1 shows that the green tea reduced significantly the dentin wear for all conditions $(p<0.01)$. For both treatments, the wear was significantly higher when abrasion was performed immediately after erosion (ERO+I-ABR) when compared to erosion alone (ERO). Regarding delayed abrasion (ERO+30-min-ABR), when rinsing was performed with water (control), a significantly higher wear was observed when compared to erosion alone (ERO). This, however, did not happen for the green tea rinse, which led to wear values that did not differ significantly from those of ERO. No significant differences in wear were observed when the conditions ERO+I-ABR and ERO+30-min-ABR were compared, for both treatments (Table 1).

\section{DISCUSSION}

The present study tested the effect of green tea on dentin wear by erosive/abrasive processes. Despite our protocol did not require the volunteers to drink the green tea, if this had to be done there would be no toxicological problems. It has been shown that tea polyphenol products in amounts equivalent to the EGCG content in 8-16 cup of green tea once a day is safe ${ }^{6}$. The response variable chosen to assess this effect was contact profilometry, which is widely used for this purpose ${ }^{20,23,33,34,36}$. For this methodology to be used, it is essential to keep the specimens moistened before and during analysis, as done in the present study, in order to avoid shrinkage of collagen fibrils, which could interfere with the results. The green tea reduced significantly dentin wear under erosive/abrasive conditions. Despite using a mechanical stylus, which is expected to cave into the organic material to some extent and give higher values than obtained with an optical device ${ }^{9}$, the amount of wear $(0.98 \mu \mathrm{m}$ loss after 100 min of erosive challenge) obtained in the present study was low when compared to a previous study from our research group $(3.6 \mu \mathrm{m}$ loss after $28 \mathrm{~min}$ of erosive 
challenge $)^{20}$. This can be explained by the different sensitivities of the equipments and the software used in both studies.

The protective effect of green tea could not be attributed to its fluoride content, since it was quite similar to that present in the negative control (water from the public supply). Additionally, its protective effect could not be attributed either to the temperature of the rinse, since the water rinse had the same temperature. One possible mechanism of action of green on the reduction of dentin erosion could be the inhibition of MMPs. If it is true, the main responsible for this effect may be the polyphenols. Green tea polyphenols, especially epigallocatechin-3-gallate (EGCG), were found to have potent and distinct inhibitory activity against MMPs in cell culture tests ${ }^{7,28}$. EGCG seems to exhibit a hydrogen bonding and hydrophobic interaction with collagenases, which is responsible for the change in the secondary structure of collagenases and consequently for their inhibition ${ }^{22}$. The EGCG concentration in the green tea used in the present study was $0.185 \mathrm{mg} / \mathrm{mL}$, which is quite above the reported $\mathrm{IC}_{50}$ values for the inhibition of MMP-2 and MMP-9, which were 10 and $0.6 \mu \mathrm{g} / \mathrm{mL}$ of EGCG, respectively ${ }^{7}$.

The in situ model used in this study allowed the formation of an acquired salivary pellicle, which might play an important role during the erosive challenge ${ }^{13}$. Considering the possibility that green tea would inhibit MMP activity and would, in turn, allow the maintenance of an organic layer on the eroded dentin, this model could also allow the MMPs from dentin as well as from saliva to influence the dentin wear. It is known that the saliva-derived MMPs could be involved in the destruction of the organic matrix ${ }^{29,31}$ and that the MMP-8 present in saliva may influence negatively the remineralization of demineralized dentin ${ }^{22}$.

Erosion was produced by a cola drink, as it is one of the most widely consumed soft drinks and exhibits erosive potential $^{19,25,27}$. Erosion was performed by extraoral immersion in cola for $5 \mathrm{~min}$, in order to produce the demineralization. It is also probable that the low $\mathrm{pH}$ of the drink has induced the activation of dentin-derived MMPs and saliva-derived MMPs, when the volunteers drank one sip of the beverage ${ }^{31}$. However, it is generally regarded that MMPs, although activated, cannot degrade the organic matrix of dentin at acidic $\mathrm{pH}^{31}$. In this protocol, the interval between each erosive challenge $(>2 \mathrm{~h}$ ), could allow for remineralization and also $\mathrm{pH}$ neutralization, which is essential for enhancing the degrading activity of the organic matrix by MMPs. However, it must be acknowledged that the protocol employed in the present study does not allow the conclusion that the effect of green tea on reducing the wear of dentin specimens was due to its inhibitory effects on MMPs activity, since we did not test this directly. Further studies focusing on the determination of the activity of MMPs in the organic layer overlying the eroded dentin after an erosive challenge could be instructive on this matter. The verification of the organic material on dentin surface by SEM could also bring additional useful information.

Tooth wear is a multifactorial condition caused by chemical (erosion) and mechanical (abrasion and attrition) processes, since the softened zone by erosive challenge is more susceptible to mechanical forces, such as abrasion ${ }^{1,20}$. Thus, studies regarding tooth wear have to consider both chemical and mechanical challenges to simulate the clinical situation. This aspect is especially important in eroded dentin, where the exposed organic matrix acts as a protective layer against further demineralization, and excessive toothbrushing could impair this matrix. However, a recent report suggested that the demineralized organic layer developed after erosive challenges was unaffected by brushing 9 . To simulate abrasive conditions which might occur during oral hygiene treatment, brushing abrasion of each specimen was performed for $30 \mathrm{~s}$ each cycle.

Regarding the abrasive wear of eroded dentin, the present results confirm previous studies showing that abrasion subsequently after an erosive attack can increase wear of acid-softened tooth surfaces ${ }^{2,23}$. However, 30 min delay of abrasion was not able to reduce dentin wear compared to brushing immediately after erosion, which was also shown in previous studies ${ }^{1,14}$. Thus, under clinical conditions, the delay of $30 \mathrm{~min}$ in toothbrushing after erosion might be ineffective on the reduction of dentin wear.

\section{CONCLUSION}

From the results of the present study, it may be concluded that the green tea reduces the dentin wear under erosive/ abrasive conditions, but additional studies are required to confirm its mechanism of action on this process. If it is confirmed that the mechanism of action of green tea on the reduction of dentin wear occurs via MMP inhibition, this will open a new perspective for the prevention/treatment of these lesions, by the design of new products containing MMP inhibitors.

\section{ACKNOWLEDGMENTS}

The authors acknowledge FAPESP (grant \#07/ 04209-0) for financial support and Prof. Dr. Rafael Mondelli for the use of the profilometer.

\section{REFERENCES}

1- Attin T, Siegel S, Buchalla W, Lennon AM, Hannig C, Becker K. Brushing abrasion of softened and remineralised dentin: an in situ study. Caries Res. 2004;38(1):62-6.

2- Attin T, Zirkel C, Hellwig E. Brushing abrasion of eroded dentin after application of sodium fluoride solutions. Caries Res. 1998;32(5):344-50.

3- Baker AH, Edwards DR, Murphy G. Metalloproteinase inhibitors: biological actions and therapeutic opportunities. J Cell Sci. 2002;115(Pt 19):3719-27.

4- Carrilho MR, Geraldeli S, Tay F, Goes MF, Carvalho RM, Tjaderhane $\mathrm{L}$, et al. In vivo preservation of the hybrid layer by chlorhexidine. J Dent Res. 2007;86(6):529-33. 
5- Chaussain-Miller C, Fioretti F, Goldberg M, Menashi S. The role of matrix metalloproteinases (MMPs) in human caries. J Dent Res. $2006 ; 85(1): 22-32$

6- Chow S, Cai Y, Hakim IA, Crowell JA, Shahi F, Brooks CA, et al. Pharmacokinetics and safety of green tea polyphenols after multiple-dose administration of epigallocatechin gallate and polyphenon $\mathrm{E}$ in healthy individuals. Clin Cancer Res. 2003;9:3312-9.

7- Demeule M, Brossard M, Page M, Gingras D, Beliveau R. Matrix metalloproteinase inhibition by green tea catechins. Biochim Biophys Acta. 2000;1478(1):51-60.

8- Ganss C, Klimek J, Starck C. Quantitative analysis of the impact of the organic matrix on the fluoride effect on erosion progression in human dentine using longitudinal microradiography. Arch Oral Biol. 2004;49(11):931-5

9- Ganss C, Schlueter N, Hardt M, von Hinckeldey J, Klimek J. Effects of toothbrushing on eroded dentine. Eur J Oral Sci. 2007;115(5):390-6.

10- Garbisa S, Sartor L, Biggin S, Salvato B, Benelli R, Albini A. Tumor gelatinases and invasion inhibited by the green tea flavanol epigallocatechin-3-gallate. Cancer. 2001;91(4):822-32.

11- Gregg T, Mace S, West NX, Addy M. A study in vitro of the abrasive effect of the tongue on enamel and dentine softened by acid erosion. Caries Res. 2004;38(6):557-60.

12- Hara AT, Ando M, Cury JA, Serra MC, Gonzalez-Cabezas C, Zero DT. Influence of the organic matrix on root dentine erosion by citric acid. Caries Res. 2005;39(2):134-8.

13- Hara AT, Ando M, Gonzalez-Cabezas C, Cury JA, Serra MC, Zero DT. Protective effect of the dental pellicle against erosive challenges in situ. J Dent Res. 2006;85(7):612-6.

14- Hara AT, Turssi CP, Teixeira EC, Serra MC, Cury JA. Abrasive wear on eroded root dentine after different periods of exposure to saliva in situ. Eur J Oral Sci. 2003;111(5):423-7.

15- Hebling J, Pashley DH, Tjaderhane L, Tay FR. Chlorhexidine arrests subclinical degradation of dentin hybrid layers in vivo. J Dent Res. 2005;84(8):741-6.

16- Kinney JH, Balooch M, Haupt DL Jr, Marshall SJ, Marshall GW Jr Mineral distribution and dimensional changes in human dentin during demineralization. J Dent Res. 1995;74(5):1179-84.

17- Kleter GA, Damen JJ, Everts V, Niehof J, Ten Cate JM. The influence of the organic matrix on demineralization of bovine root dentin in vitro. $\mathrm{J}$ Dent Res. 1994;73(9):1523-9.

18- Klont B, ten Cate JM. Remineralization of bovine incisor root lesions in vitro: the role of the collagenous matrix. Caries Res. 1991;25(1):3945 .

19- Magalhães AC, Rios D, Delbem AC, Buzalaf MA, Machado MA. Influence of fluoride dentifrice on brushing abrasion of eroded human enamel: an in situ/ex vivo study. Caries Res. 2007;41(1):77-9.

20- Magalhães AC, Rios D, Moino AL, Wiegand A, Attin T, Buzalaf MA. Effect of different concentrations of fluoride in dentifrices on dentin erosion subjected or not to abrasion in situ/ex vivo. Caries Res. 2008;42(2):112-6.

21- Mazzoni A, Mannello F, Tay FR, Tonti GA, Papa S, Mazzotti G, et al. Zymographic analysis and characterization of MMP-2 and -9 forms in human sound dentin. J Dent Res. 2007;86(5):436-40.

22- Nordbo H, Leirskar J, Ngo H, Mount GJ, Wahlgren J. The influence of a matrix metalloproteinase on the remineralization of artificially demineralized dentin. Oral Health Prev Dent. 2003;1(4):267-72.
23- Ponduri S, Macdonald E, Addy M. A study in vitro of the combined effects of soft drinks and tooth brushing with fluoride toothpaste on the wear of dentine. Int J Dent Hyg. 2005;3(1):7-12.

24- Ramires I, Maia LP, Rigolizzo dos Santos D, Lauris JR, Buzalaf MA. [External control over the fluoridation of the public water supply in Bauru, SP, Brazil]. Rev Saude Pública. 2006;40(5):883-9.

25- Rios D, Honório HM, Magalhães AC, Delbem AC, Machado MA, Silva SM, et al. Effect of salivary stimulation on erosion of human and bovine enamel subjected or not to subsequent abrasion: an in situ/ex vivo study. Caries Res. 2006;40(3):218-23.

26- Saito ST, Welzel A, Suyenaga ES, Bueno F. A method for fast determination of epigallocatechin gallate (EGCG), epicatechin (EC), catechin (C) and caffeine (CAF) in green tea using HPLC. Ciênc Tecnol Aliment. 2006;26(2):394-400.

27- Sales-Peres SH, Pessan JP, Buzalaf MA. Effect of an iron mouthrinse on enamel and dentine erosion subjected or not to abrasion: an in situ/ex vivo study. Arch Oral Biol. 2007;52(2):128-2.

28- Sartor L, Pezzato E, Dell'Aica I, Caniato R, Biggin S, Garbisa S. Inhibition of matrix-proteases by polyphenols: chemical insights for antiinflammatory and anti-invasion drug design. Biochem Pharmacol. 2002;64(2):229-37.

29- Strijp AJ van, Jansen DC, DeGroot J, ten Cate JM, Everts V. Hostderived proteinases and degradation of dentine collagen in situ. Caries Res. 2003;37(1):58-65.

30- Sulkala M, Tervahartiala T, Sorsa T, Larmas M, Salo T, Tjaderhane L. Matrix metalloproteinase-8 (MMP-8) is the major collagenase in human dentin. Arch Oral Biol. 2007;52(2):121-7.

31- Tjäderhane L, Larjava H, Sorsa T, Uitto VJ, Larmas M, Salo T. The activation and function of host matrix metalloproteinases in dentin matrix breakdown in caries lesions. J Dent Res. 1998;77(8):1622-9.

32- West NX. Dentine hypersensitivity. Monogr Oral Sci. 2006;20:17389.

33- Wiegand A, Egert S, Attin T. Toothbrushing before or after an acidic challenge to minimize tooth wear? An in situ/ex vivo study. Am J Dent. 2008;21(1):13-6.

34- Wiegand A, Gutsche M, Attin T. Effect of olive oil and an olive-oilcontaining fluoridated mouthrinse on enamel and dentin erosion in vitro. Acta Odontol Scand. 2007;65(6):357-61.

35- Wiegand A, Laabs KA, Gressmann G, Roos M, Magalhaes AC, Attin T. Protection of short-time enamel erosion by different tetrafluoride compounds. Arch Oral Biol. 2008;53(6):497-502.

36- Wiegand A, Stock A, Attin R, Werner C, Attin T. Impact of the acid flow rate on dentin erosion. J Dent. 2007;35(1):21-7. 